\title{
EFEKTIVITAS PROGRAM PRAKTEK LAPANGAN MAHASISWA BERBASIS PENEMPATAN PADA LEMBAGA MITRA DEPARTEMEN PENDIDIKAN LUAR SEKOLAH (STUDI PADA MAHASISWA PPL DEPARTEMEN PLS FIP UPI)
}

\author{
Oong Komar \\ Universitas Pendidikan Indonesia \\ prof.oongkomar@upi.edu
}

\begin{abstract}
Program Field (PPL) as a program that instills applicative capabilities integrated with the entire previous learning experiences into the training program of the performance of all matters relating to the working positions, both teaching and learning activities as well as other tasks. However, the observation while not showing state competence and professional working systematic order. The question is: (1) What is the general profile of each institution used PLS partners PPL? (2) Which PLS PPL partner institutions that have a high tendency PPL effective implementation? (3) What is the level of effectiveness of the PPL student at a partner institution PLS department? This study aims to assess the effectiveness of the PPL student placement based on PLS department partner institutions. Performed using a quantitative approach with data collection questionnaire scale. The results showed the effectiveness of the PPL student placement based on PLS department partner agencies needs to be improved and suggested further implementation of PPL housed at partner institutions whose programs CLC complete or appropriate placement rolling competence PPL expectations.
\end{abstract}

Keywords: qualification, competence

\section{A. PENDAhuluan}

Menurut Menteri PPN/KepalaBappenas (2013), untuk menyediakan tenaga kerja dengan kompetensi yang selaras, ada 2 (dua) cara, yaitu pertama, melalui jalur pendidikan formal, dan kedua, melalui jalur pelatihan. Salah satu jalur yang diterapkan dalam jalur pendidikan formal di jenjang perguruan tinggi adalah program pengalaman lapangan atau praktek pengalaman lapangan. Istilah Praktek Pengalaman Lapangan (PPL) disebut juga PLP, PKL, job training, internship, praktek profesi dan koas. Posisi PPL dalam pelaksanaan pendidikan sistem concecutive merupakan bagian terintegrasi setelah lulus program akademik dan diselenggarakan untuk menciptakan lulusan profesional. Agar mengikuti program profesi ini dengan baik, mahasiswa perlu menguasai pengalaman keterampilan dasar profesi dimana penyediaan program untuk memenuhi kebutuhan tersebut. PPL berfungsi memadukan pengetahuan antara yang telah didapatkan selama di perkuliahan dengan aktualisasinya. Konsep pendidikan link and match, menegaskan PPL dalam rangka memperoleh pengetahuan praktis (practical knowledge), pengalaman profesionalitas (experiences of professionality), kemampuan analistis teoritis (theoriticalanalytical capability) dan hubungan industrial (industrial relationship). PPL sebagai program yang menanamkan kemampuan aplikatif dan terpadu dengan seluruh pengalaman belajar sebelumnya ke dalam program pelatihan berupa kinerja dari semua hal yang berkaitan dengan jabatan kerja, baik kegiatan belajar mengajar maupun tugas-tugas lainnya. PPL yang di laksanakan pada instansi - instansi pemerintah atau swasta untuk meningkat dan memperluas pengetahuan bagi mahasiswa mengenai lingkungan kerja. 
Guru sangat perlu meningkatkan peranan dan kemampuan profesionalnya. Tanpa adanya kecakapan yang maksimal yang dimiliki oleh guru maka kiranya sulit bagi guru tersebut mengembang dan melaksanakan tanggung jawabnya dengan cara yang sebaik-baiknya. Peningkatan kemampuan itu meliputi kemampuan untuk melaksanakan tanggung jawab dalam melaksanakan tugas-tugas di dalam sekolah dan kemampuannya yang diperlukan untuk merealisasikan tanggung jawabnya di luar sekolah. Kemampuan-kemampuan itu harus dipupuk dalam diri pribadi guru sejak ia mengikuti pendidikan guru sampai ia bekerja.

Pelaksanaan PPL terjadwal secara sistematis dibimbingan dosen pembimbing dan guru pamong, meliputi kegiatan pembelajaran terbatas (Micro Teaching), pelatihan terbimbing, dan pelatihan mandiri yang diarahkan pada terbentuknya kemampuan keguruan. PPL diharapkan tidak hanya mampu mengaplikasikan ilmu dan teori-teori yang telah didapatkan di perkuliahan, tetapi juga harus mampu menimba pengetahuan baru dan bekerja sama di tempat mereka melakukan praktek profesi ini, baik dalam dunia usaha swasta maupun pemerintah. Selain itu, PPL dipandang perlu karena di dalamnya tercakup ketiga Tri Dharma Perguruan Tinggi yaitu Pendidikan, Penelitian, dan Pengabdian. Bahkan dengan tuntutan pertumbuhan dan perkembangan ekonomi yang cepat berubah, maka PPL akan menambahkan kemampuan untuk mengamati, mengkaji, serta menilai antara teori dengan kenyataan yang terjadi di lapangan. Sehingga pada akhirnya dapat meningkatkan kualitas managerial mahasiswa dalam mengamati permasalahan dan persoalan, baik dalam bentuk aplikasi teori maupun kenyataan yang sebenarnya.

Pemikiran diatas, mengarah pada kajian mengenai PPL yang berkaitan dengan: (1) Memantapkan, meningkatkan dan memperluas keterampilan yang di miliki oleh mahasiswa dalam dunia kerja; (2) Mengembangkan dan memantapkan sikap professional yang di perlukan untuk memasuki dunia kerja sesuai dengan bidang masing-masing; (3) Sarana komunikasi antara prodi dengan instansi atau kantor tempat pelaksanaan PPL; (4) Memberikan kesempatan kepada mahasiwa beradaptasi dengan suasana atau iklim lingkungan kerja yang sebenarnya baik sebagai pekerja mandiri terutama yang berkenan dengan di siplin kerja; dan (5) Memberikan masukan dan umpan balik guna perbaikan dan pengembangan pendidikan.

Bertolak dari pemikiran di atas,rumusan masalah penelitian ini adalah: Bagaimanakah efektifitas pelaksanaan PPL mahasiswa pada lembaga mitra departemen PLS? Rumusan masalah tersebut dijabarkan menjadi pertanyaan penelitian sebagai berikut:

1. Bagaimanakah profil tiap lembaga mitra PLS yang digunakan PPL?

2. Manakah lembaga mitra PPL PLS yang cenderung tinggi efektivitas pelaksanaan PPLnya?

3. Bagaimanakah tingkatefektifitas pelaksanaan PPL mahasiswa pada lembaga mitra departemen PLS?

\section{B. KAJIAN LITERATUR}

Pelaksanaan PPL terjadwal secara sistematis dibimbingan dosen pembimbing dan guru pamong, meliputi kegiatan pembelajaran terbatas (Micro Teaching), pelatihan terbimbing, dan pelatihan mandiri yang diarahkan pada terbentuknya kemampuan keguruan. PPL bertolak dari asumsi bahwa PPL merupakan titik kulminasi (puncak) dari seluruh program pendidikan profesi yang telah dihayati dan dialami oleh mahasiswa, maka PPL adalah suatu program pelatihan untuk penerapan, penanaman dan pembentukan profesi.

Dipandang dari sudut kurikulum, PPL adalah mata kuliah yang dipersyaratkan dalam pendidikan prajabatan guru. PPL dirancang untuk menyiapkan mahasiswa calon guru 
untuk memiliki atau menguasai kemampuan keguruan yang menyeluruh dan terpadu, sehingga setelah mahasiswa tersebut menjadi guru, agar dapat mengemban tugas dan tanggungjawabnya secara profesional. Selain itu, PPL adalah seperangkat komponen pelatihan prajabatan guru yang berlangsung dalam siklus teori dan praktek secara berlapis ulang pada setiap langkah yang dipersyaratkan dalam program pelatihan tersebut. Setiap langkah dalam komponen pelatihan tersebut selalu mengacu pada teori yang telah dipelajari dan menuju pada praktek pelaksanaan pembelajaran yang efektif dan efisien dalam berbagai kondisi.

PPL adalah salah satu bentuk implementasi secara sistematis dan sinkron antara program pendidikan di kampus dengan program penguasaan keahlian yang diperoleh melalui kegiatan kerja secara langsung didunia kerja untuk mencapai tingkat keahlian tertentu. PPL dapat meningkatkan relevensi pendidikan dengan mengarahkan pada pengembangan system hubungan antara dunia pendidikan dan dunia usaha. PPL dapat meningkatkan mutu pendidikan dengan diperolehnya keterampilan keahlian dari dunia usaha yang tidak diajarkan di kampus.

Berangkat dari terlalu tingginya harapan terhadap guru untuk melaksanakan tugas yang seharusnya dilakukan oleh tenaga profesional. Kini (dua puluh tiga tahun kemudian) kita masih dihadapkan kepada tuntutan agar guru kita dari Pra- Sekolah sampai SLTA memiliki kemampuan profesional melaksanakan pendekatan baru dalam penyelenggaraan pendidikan, agar pendidikan kita tambah relevan dan bermutu sesuai dengan tuntutan perkembangan masyarakat.

Faktor yang menuntut guru harus profesional, di antaranya heterogenitas peserta didik dalam berbagai dimensi (intelektual, kultural, dan ekonomi), terus berkembangnya ilmu pengetahuan dan teknologi sebagai sumber obyek belajar dan terus berubahnya masyarakat dengan segala aspek tuntutannya. Tugas guru dalam era globalisasi perlu merancang, memilih bahan pelajaran dan strategi pembelajaran yang sesuai dengan latar belakang peserta didik yang berbeda, serta mengelola proses pembelajaran secara taktis dan menyenangkan, memilih media belajar dan merancang program evaluasi yang sesuai dengan tujuan pendidikan yang berorientasi kepada penguasaan kompetensi. Bahkan untuk memperbaiki dan meningkatkan mutu pendidikan diperlukan para pendidik yang profesional yang ditopang dengan pengelola kependidikan yang profesional pula dan perlu kebersamaan dalam menjalankannya.

Tim Pengembang Ilmu Pendidikan FIP-UPI (2007:392) menyebutkan bahwa "Kinerja standar atau kinerja profesional merupakan perwujudan dari tanggung jawab profesional (professional responsibility), sebab "professional responsibility is the core of professionalism" yang artinya tanggung jawab profesional adalah inti dari sifat profesional." Bekerja secara profesional adalah bekerja secara terencana dan sistematis, bekerja secara cerdas masalah etika, efisien, efektif. Tanggung jawab profesi juga menyangkut karena pelaksanaan tugas profesi berpegang teguh dan sejalan dengan etika suatu profesi.

Memperhatikan ciri-ciri mendasar tentang profesi dan arah pengembangan profesi serta pembinaan tenaga profesional, dikonsepsikan adanya komponen-komponen pokok yang membentuk profesi itu dalam konsep atau teori, praksis dan praktiknya. Ada tiga komponen profesi yang membentuk trilogi profesi pada umumnya, yaitu: dasar keilmuan, substansi profesi, dan praktek profesi.

Ada tiga komponen profesi yang membentuk trilogi profesi pada umumnya, yaitu: dasar keilmuan, substansi profesi, dan praktek profesi. Komponen dasar keilmuan memberikan landasan bagi calon tenaga profesional 
dalam wawasan, pengetahuan, keterampilan, nilai dan sikap berkenaan dengan profesi yang dimaksud. Komponen substansi profesi membekali calon profesional apa yang menjadi fokus dan objek praktis spesifik pekerjaan profesionalnya. Komponen praktik mengarahkan calon tenaga profesional untuk menyelenggarakan praktik profesinya itu kepada sasaran pelayanan atau pelanggan secara tepat dan berdaya guna. Penguasaan dan penyelenggaraan trilogi profesi secara mantap merupakan jaminan bagi suksesnya penampilan profesi tersebut demi kebahagiaan sasaran pelayanan. Penguasaan ketiga komponen profesi tersebut diperoleh di dalam program pendidikan profesi dan pendidikan akademik yang mendasarinya.

Untuk menjadi profesionalharus menguasai dan memenuhi ketiga komponen/trilogi profesi, yaitu:

1. Komponen dasar keilmuan memberikan landasan bagi calon tenaga profesional dalam wawasan, pengetahuan, keterampilan, nilai dan sikap berkenaan dengan profesi yang dimaksud;

2. Komponen substansi profesi membekali calon profesional apa yang menjadi fokus dan objek praktis spesifik pekerjaan profesionalnya; dan

3. Komponen praktik profesi mengarahkan calon tenaga profesional untuk menyelenggarakan praktik profesinya itu kepada sasaran pelayanan atau pelanggan secara tepat dan berdaya guna.

\section{METODE PENELITIAN}

Tempat penelitian berada di wilayah Provinsi Jawa Barat. Menggunakan pendekatan kuantitatif dengan metode preexperimental design dalam bentuk one group pretest - posttest design. Analisis data menggunakan rumus interval tabel konversi skor dan mengukur perbedaan dengan uji t. Penelitian inimemiliki target population adalah pihak-pihak terkait para stakeholder pendidikan luar sekolah dan acces able population adalah pihak-pihak terkait departemen/program studi pendidikan luar sekolah FIP-UPI. Subyek responden (yang dipilih secara tertentu) penelitian terdiri atas lembaga yang digunakan dan mahasiswa yang sedang PPL.

Data penelitian ini adalah gambaran pelaksanaan PPL mahasiswa berdasarkan penempatannya pada lembaga mitra PLS. Sesuai dengan kebutuhan tersebut, instrumen yang digunakan adalah skala pelaksanaan PPL yang dikembangkan berdasarkan konstruk standar pelaksanaan PPL. Pengembangan instrumen dimulai denganmerumuskan definisi operasional, membuat kisi-kisi, menyusun pernyataan instrumen dan menguji kelayakan instrumen baik validitas konstruk (validitas dan reliabilitas), maupun validitas konten (kesesuaian isi dan keterbacaan kalimat/redaksional).

Bertolak dari asumsi di atas, rancangan penelitian ini memiliki bagan alur sebagai berikut. 


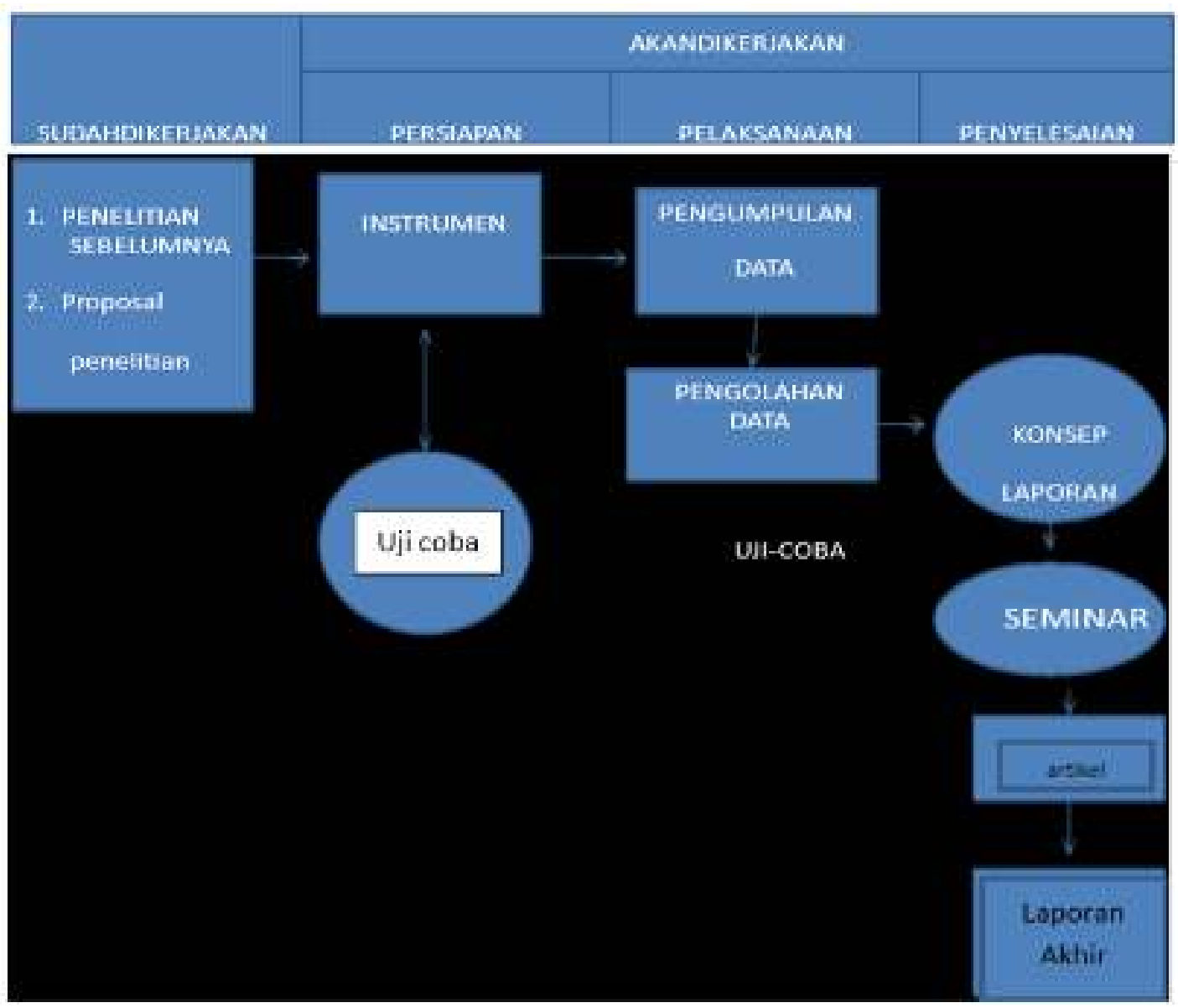

Gambar 1

Alur Penelitian

\section{HASIL DAN PEMBAHASAN}

Penelitian ini dilakukan pada responden mahasiswa PPL PLS tahun 2017. Tempat PPL lembaga mitra PLS antara lain UPT Paud Dikmas, Sanggar Kegiatan Belajar, BPP Pertanian, BBP Kesehatan dan BPPK Sosial. Menggunakan instrumen yang telah melewati serangkaian tahapan pengembangan instrumen, yaitu penyusunan konstruk (kisi-kisi dan pertanyaan), judgement (keseuaian isi dan keterbacaan) dan uji coba instrumen agar ditemukan nilai validitas dan reliabilitas. Untuk uji validitas menggunakan rumus pearson dan uji satu sisi dengan tarap signifikansi 0,05 pada posisi $r$ hit $>r$ tab dinyatakan valid. Untuk uji reliabilitas menggunakan rumus spearman dan uji signifikansi guilford pada posisi besaran $r>0,71$.

Analisis data melalui langkah awal verifikasi data, konversi klasifikasi (mengubah skor mentah ke skor matang agar data menggambarkan \% klasifikasi SS, S, TS, STS), uji t untuk membandingkan apakah sama ataukah berbeda antara nilai data pre test dengan post test dan terakhir uji signifikansi. Hasilnya menunjukkan skor post test melebihi skor pre test dan pada uji signifikansi skor tersebut menunjukkan kesamaan. Artinya, pelaksanaan PPL saat ini belum optimal efektif.

\section{E. SIMPULAN DAN SARAN}

Berdasarkan pendekatan profesi, pelaksanaan PPL saat ini belum optimal efektif. Tiap lembaga mitra PPL harus terus ditingkatkan efektivitasnya. Perlu penjabaran yang menggambarkan kompetensi yang di PPL.

Sarannya, untuk pelaksanaan PPL selanjutnya bertempat pada lembaga 
mitra PKBM yang programnya lengkap atau rolling penempatan sesuai kompetensi harapan PPL.

\section{DAFTAR PUSTAKA}

Danim, Sudarwan. (2010). Karya Tulis Inovatif Sebuah Pengembangan Profesi Guru, Penerbit : PT. Remaja Rosdakarya, Bandung.

Djamarah, Saiful Bakri. (1994). Prestasi Belajar dan Kompetensi Guru, Penerbit : Usaha Nasional, Surabaya.

Depdiknas. (2003). Manajemen Berbasis Sekolah, Direktorat Jenderal Pendidikan Dasar dan Menengah, Jakarta.

Hamalik, Oemar. (2003). Proses Belajar Mengajar, Penerbit : Bumi Aksara, Jakarta.

H.E. (2010). Penelitian Tindakan Sekolah Meningkatkan Produktivitas Sekolah, Penerbit : PT Remaja Rosdakarya, Bandung.

Mulyasa, E. (2004). Menjadi Kepala Sekolah Profesional dalam Konteks Menyukseskan $M B S$ dan $K B K$, Penerbit : PT Remaja Rosdakarya, Bandung.

Peraturan Pemerintah Nomor 74 Tahun 2008 tentang Guru (Lembaran Negera RI Tahun 2008 Nomor 194).

Peraturan Menteri PAN dan Reformasi Birokrasi No. 16 Tahun 2009 tentang Jabatan Fungsional Guru dan Angka Kreditnya.

Roestiyah N.K. (1986). Masalah-masalah Ilmu Keguruan, Penerbit : Bina Aksara, Jakarta.

Saud, Udin Saefudin. (2009). Pengembangan Profesi Guru, Penerbit : CV. Alfabeta, Bandung.

Sudjana, Nana. (2005). Dasar-dasar Proses Belajar Mengajar, Penerbit : Sinar Baru Algensindo, Bandung.
Suderadjat, Hari. (2004). Implementasi Kurikulum Berbasis Kompetensi (KBK) Pembaharuan Pendidikan dalam Undang-undang Sisdiknas 2003, Penerbit : CV Cipta Cekas Grafika, Bandung.

Undang-Undang RI Nomor 14 Tahun 2005 tentang Guru dan Dosen (Lembaran Negara RI Tahun 2005 Nomor 157).

Wijaya, Cece, dan A. Tabrani Rusyan. (1992). Kemampuan Dasar Karyawan dalam Proses Belajar Mengajar, Penerbit : Remaja Rosdakarya, Bandung. http://www.kompasiana.com/ahm adturmu zi/pengembangankompetensiguru-menujupelaksanaan-dantanggung-jawabsecaraprofesional_550e0e63a333 $11 \mathrm{bc} 2 \mathrm{db}$ a $7 d d f$ 